\title{
A mouse model of acute exacerbations of lung inflammation in COPD with both steroid-sensitive and steroid-insensitive features
}

\author{
V Russell, A Connolly, C Jagger, D Spicer, P Woodman, J Dlugozima, A Young \\ From 2nd Cross Company Respiratory Symposium \\ Horsham, UK. 6-7 September 2012
}

\section{Introduction}

Exposure to tobacco smoke (TS) for 4 days induces a reproducible steroid-insensitive lung inflammation in the mouse. The effect of adding the viral mimetic poly IC (PIC) to TS-exposed mice was examined with the aim of defining the translational aspects of the model to human disease.

\section{Methods}

Female mice (C57BL16) were exposed daily to TS (Marlboro 100 cigarettes) for $4 \mathrm{~d}$. Control groups were exposed to air. Saline or PIC was administered intra-nasally. Mice were killed 4-120hrs after the last exposure, the lungs lavaged and cells (totals and differential) counted. Single oral doses of Dexamethasone (DEX $0.3 \mathrm{mg} / \mathrm{kg}$ ) or Roflumilast (ROF $5 \mathrm{mg} / \mathrm{kg}$ ) were administered $2 \mathrm{hrs}$ after the final challenge. To investigate the kinetics of the exaggerated inflammatory response, a single dose of DEX was given after the final challenge and effects followed for $120 \mathrm{hrs}$.

\section{Results}

TS-exposure caused a significant cellular infiltration (total cells $\approx 0.3$ million) into the lung, which was inhibited by ROF but not DEX. In non-TS exposed mice, PIC induced an inflammatory response (total cells $\approx 0.3$ million) which was not inhibited by either DEX or ROF. Administration of PIC in addition to TS-exposure induced an exaggerated inflammatory response (total cells $\approx 1.1$ million) which was significantly greater than the additive effect of the two stimuli. This enhanced inflammatory response peaked $24 \mathrm{hrs}$ after the last exposure before slowly declining. Neutrophils were the predominant infiltrating cell type over the first $48 \mathrm{hrs}$. Macrophage numbers were also elevated, with a sustained increase at 24-72 hrs. Lymphocyte numbers also increased and peaked at 48-72hrs after exposure. The peak exacerbated inflammation at $24 \mathrm{hrs}$ after exposure was significantly inhibited by both ROF $(53 \%, \mathrm{p}<0.05)$ and DEX (56\%, $\mathrm{p}<0.05)$, in contrast to the reproducible lack of efficacy of DEX in the TS or PIC groups. The time course revealed that a single dose of DEX given after the last exposure reduced the exaggerated response over the entire $120 \mathrm{hr}$ study period but was unable to fully resolve the inflammation.

\section{Conclusions}

TS-exposure for 4 days induced a lung inflammation which was insensitive to steroids. Addition of PIC elicited a markedly enhanced inflammatory response that resolved over $120 \mathrm{hrs}$ and was sensitive to both steroids and Roflumilast, mimicking features of human COPD.

Published: 14 August 2013

doi:10.1186/1476-9255-10-S1-P32

Cite this article as: Russell et al:: A mouse model of acute exacerbations of lung inflammation in COPD with both steroid-sensitive and steroidinsensitive features. Journal of Inflammation 2013 10(Suppl 1):P32.

Argenta Discovery, Spire Green, Harlow, Essex, UK

C 2013 Russell et al; licensee BioMed Central Ltd. This is an Open Access article distributed under the terms of the Creative Commons 